Article

\title{
Coupled Spatiotemporal Characterization of Monsoon Cloud Cover and Vegetation Phenology
}

\author{
Daniel Sousa ${ }^{1, * \mathbb{D}}$, Christopher Small ${ }^{1}$, Andrew Spalton ${ }^{2}$ and Andy Kwarteng ${ }^{3}$ \\ 1 Lamont-Doherty Earth Observatory, Columbia University, Palisades, NY 10964, USA; csmall@columbia.edu \\ 2 Diwan of Royal Court, P.O. Box 190, PC 100, Muscat, Oman; spalt@omantel.net.om \\ 3 Remote Sensing and GIS Center, Sultan Qaboos University, P.O. Box 33, Al Khod, PC 123, Oman; \\ andykwarteng@hotmail.com \\ * Correspondence: d.sousa@columbia.edu; Tel.: +1-530-304-4992
}

Received: 23 March 2019; Accepted: 16 May 2019; Published: 21 May 2019

\begin{abstract}
In monsoonal ecosystems, vegetation phenology is generally modulated by the timing and intensity of seasonal precipitation. Seasonal precipitation is often characterized by substantial interannual variability in both space and time. A rigorous quantitative understanding of the ecology of the landscape requires spatially explicit information regarding the strength of the relationship between seasonal precipitation and vegetation phenology, as well as the interannual variability of the system. For this information to be accurately estimated, it must be based on spatially and temporally consistent measurements. The optical satellite image archive can provide these measurements. Satellite imagery offers observations of both a) atmospheric parameters such as the timing and spatial extent of monsoon cloud cover; and, b) phenological parameters, such as the timing and spatial extent of vegetation green-up and senescence. This work presents a method to capture both atmospheric and phenological parameters from an optical image time series. The method uses Empirical Orthogonal Function (EOF) analysis of a single spectral index for unified characterization of the spatiotemporal dynamics of both monsoon cloud cover and vegetation phenology. This is made possible by leveraging well-understood differences in the visible and near infrared reflectance of green vegetation, soil, and clouds. Image time series are transformed into a temporal feature space (TFS) that is comprised of low-order Principal Components. The structure of the temporal feature space reveals spatiotemporally distinct annual cycles of both cloud cover and vegetation phenology. In order to illustrate this technique, we apply it to the retrospective analysis of a seasonal cloud forest in the Dhofar Mountains of the southern Arabian Peninsula. Our results quantify known (but previously unmapped) local gradients in monsoon duration and vegetation community response. Individual ecological subsystems are also clearly distinguishable from each other, and consistent elevation gradients emerge within each subsystem. Novel observations also emerge, such as regreening/early greening events and spatial patterns in cloud duration. The method is conceptually straightforward and could be applied to characterize other monsoon environments anywhere on Earth.
\end{abstract}

Keywords: spatiotemporal; daily MODIS; monsoon; vegetation phenology; EOF; temporal mixture model

\section{Introduction}

Monsoons influence a wide range of ecologically and societally important landscapes. The annual reversal of winds characteristic of monsoon climates generally results in strong seasonality in patterns of rainfall, temperature, and humidity [1]. Because these parameters are often linked to plant physiology, wild and managed vegetation communities alike rely on the monsoon for cues associated with leaf out, growth, and senescence [2]. Mean and interannual variability of the monsoon ultimately controls 
overarching ecosystem parameters like nutrient pulses [3,4] and net primary production [5,6]. Where they are present, monsoons drive phenology.

Significant year-to-year variations in the timing, duration, and spatial extent of seasonal rains can occur in monsoon environments [7]. Because of the relationship between precipitation and plant growth, the interannual variability of the monsoon can cause fluctuations in vegetation abundance and phenological timing (e.g., [8]). Interannual variability (along with the potential for multi-year trends) in monsoon environments is a question of significant interest to the biogeoscience community, policymakers, and the public, because of the potential implications for management of coupled human-natural systems (e.g., [9-11]). However, accurate quantification of variability and/or trends in monsoon environments requires consistent measurements of the biogeophysical system across both space and time.

Optical satellite imaging is one source of abundant, intercalibrated measurements of the atmosphere and Earth surface. Multispectral sensors like MODIS (the Moderate Resolution Imaging Spectroradiometer) [12], Landsat [13], and Sentinel-2 [14], measure reflected solar radiance in order to provide estimates of Earth's reflectance. Field and laboratory reflectance spectra of many Earth materials have been measured, allowing for accurate, spatially and temporally explicit inference of the abundance of these materials from multispectral imagery (e.g., [15-17]). Decades of satellite observations now exist and are of sufficient quantity and quality to support robust spatiotemporal analysis. This data archive is freely available, global in scope, and growing with improving resolution in space and time as new satellite constellations become operational and future missions are planned.

This work presents an approach to spatiotemporal analysis that relies on a single parameter to reliably discriminate between green vegetation, soil, and clouds. The parameter that we use is the Normalized Difference Vegetation Index (NDVI) [18]. Differences in NDVI among these three common Earth materials are due to their fundamental physical and chemical properties. The broad consistency of the multispectral reflectance properties of these materials, as well as the generality of their relative seasonal cycles, suggests that this approach is likely to be sufficiently general to be profitably applied in other monsoon environments worldwide.

Our analytic approach begins by applying Empirical Orthogonal Function (EOF) analysis [19] to an image time series of NDVI. EOF analysis is a commonly used tool in climatology, meteorology, and oceanography [20-22]. We then extend the traditional EOF analysis by using the topology of the Temporal Feature Space (TFS) composed of the low order Principal Components to characterize the continuum of temporal patterns that are present in the image time series, as described by [23]. The combination of the topology of the temporal feature space, its geographic manifestation as spatial Principal Components, and the structure of the temporal EOFs provides a basis for separating deterministic spatiotemporal patterns from stochastic variability without the need for a priori assumptions about the form of the spatial or temporal processes that may or may not be represented in the data. Subsequent investigation of the resulting temporal feature space allows for discrimination among regions with statistically distinct monsoonal-phenological cycles. Gradations and abrupt transitions among regions are both clearly identifiable. Seasonal and interannual differences in monsoon timing and vegetation phenology within and among these regions are also visually evident and easily quantifiable.

\subsection{Purpose}

The purpose of this study is to introduce a method of quantitative spatiotemporal characterization and modeling of cloud cover and vegetation phenology for monsoonal landscapes. In so doing, we demonstrate an example application of the method and illustrate its potential to:

- determine the number and location of distinct spatiotemporal patterns of monsoon-phenological activity,

- identify relationships between vegetation abundance/phenology and duration of cloud cover, and

- quantify spatially explicit historical trends (if any) in the atmosphere-biosphere system. 
Our example application generates results that are consistent with field observations and local knowledge. Novel features of the study area are also identified, which, to our knowledge, have not been previously documented. While the effect of cloud cover has long been recognized to often (but not always) reduce the NDVI of a pixel (e.g., [24]), to our knowledge the NDVI differential between clouds and the land surface has not yet been leveraged for spatiotemporal phenological characterization using EOF analysis. Importantly, the method developed in this study does not rely on any location-specific parameters, and so is expected to be sufficiently general for application in any landscape in which seasonal precipitation patterns strongly influence wild or managed vegetation.

\subsection{Example Study Area}

The location chosen to demonstrate this spatiotemporal analysis methodology is the Dhofar Mountain Chain (Jabal Dhofar) of southern Oman. Jabal Dhofar was chosen on the basis of its monsoon-dominated ecohydrology, endemic biodiversity, and the authors' familiarity with the region. Jabal Dhofar is comprised of three contiguous mountains: Jabal Al Qamar, Jabal Al Qara, and Jabal Samhan. The three mountains each abruptly rise from near sea level to elevations over $1000 \mathrm{~m}$. The eastern Jabal Samhan is the highest, precipitously rising from the coastal plain to nearly $1800 \mathrm{~m}$. Jabal Al Qara lies immediately west of Jabal Samhan. Its coastward face is characterized by deeply incised valleys (wadis), while the rangetop forms a gradual ramp up into the persistently arid desert of the Nejd and the Empty Quarter (Rub' al Khali) of the Arabian Peninsula. The Salalah coastal plain lies between Jabal Al Qara and the Arabian Sea. Jabal Al Qamar is the westernmost of the three mountains, rising more abruptly from the sea and grading more rapidly into the Nejd than Jabal Al Qara. For an introduction to the geography of Jabal Dhofar, see [25]; for broader context on human-environment interactions in the region, see [26-28].

The climate of Dhofar is dominated by the annual Arabian monsoon. The monsoon occurs as the result of seasonal winds pushing warm, moist air from the Arabian Sea inland onto Jabal Dhofar. This results in persistent ground-level clouds, light rain, and generally cool and moist conditions from roughly mid-June to mid-September. Rain gauges generally record between 100 and $400 \mathrm{~mm}$ during the monsoon, accounting for $67.5 \%$ of their annual signal [29]. However, gauges incompletely measure the total water delivery because a substantial fraction comes as horizontal precipitation: atmospheric water that is directly captured by collision as suspended droplets are intercepted by objects on the land surface. Horizontal precipitation has been a subject of study for its importance in the local ecohydrology [30-34] as well as its potential capture for anthropogenic uses (e.g., [35,36]). While some horizontal precipitation occurs on the coastal plain, the majority is located on the coastward slopes of Jabal Al Qamar and Jabal Al Qara.

The relative geographic isolation and distinct microclimate of Jabal Dhofar contribute to high endemic biodiversity and a unique floral assemblage, as documented in detail by $[37,38]$. The coastward slopes and wadis of Jabal Al Qara and Jabal Al Qamar are each home to a seasonal cloud forest ecosystem that is dominated by the endemic Anogeissus dhofarica tree, while broad rolling grasslands dominate the ridges and plateaus. A diverse fauna includes the iconic and critically endangered Arabian Leopard [39]. Camels, cattle, goats, and feral donkeys feed on the woodlands and grasslands and are found throughout.

Figure 1, panels A-D show the way in which the topographic, atmospheric, and biospheric factors that are described above contribute to multispectral reflectance as observed by MODIS. Topographic relief (data: Shuttle Radar Topography Mission (SRTM), Figure 1A) limits the extent to which monsoon cloud cover and precipitation, blown northward from the Arabian Sea during the monsoon, can penetrate inland. The landscape is dry before the monsoon (Figure 1B), but water is provided through monsoon precipitation (Figure 1C), which results in extensive vegetation greening during and immediately following the monsoon (Figure 1D). Example VNIR field spectra (E and F) demonstrate the differences between green vegetation, non-photosynthetic (e.g., senesced) vegetation, soil, and cloud at $<3 \mathrm{~nm}$ spectral resolution. MODIS is a multispectral sensor, integrating the true VNIR 
reflectance continuum (solid lines) into four measurements (points) as characterized by the sensor spectral response function (dashed lines), resulting in differences in NDVI (inset text labels). Through time, example grassland and forest pixels $(\mathrm{G}$ and $\mathrm{H}$ ) show clear phenological differences in maximum greenness and rate of senescence. The EOF analysis presented next will map these phenological differences among pixels on the basis of covariance.
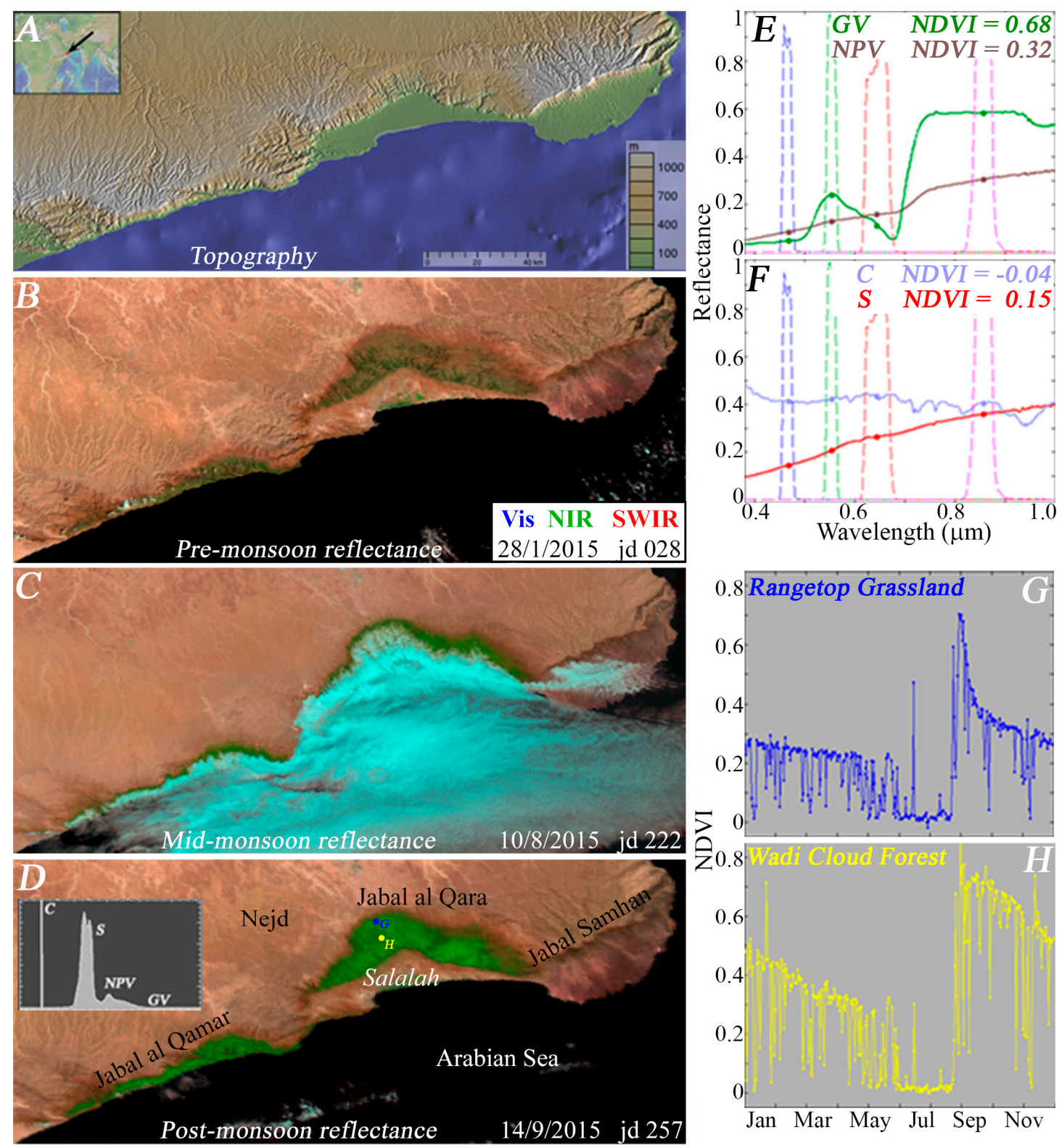

Figure 1. Index map of Jabal Dhofar. Topography (A, $30 \mathrm{~m}$ SRTM) limits the extent to which monsoon moisture can penetrate inland when blown northward from the Arabian Sea. The landscape is dry before the annual monsoon (B). Precipitation is then delivered to Jabal Dhofar and the coastal plain (C), resulting in extensive green-up during and immediately following the monsoon (D). Green vegetation, non-photosynthetic vegetation/soil, and clouds can be differentiated on the basis of Normalized Difference Vegetation Index (NDVI), as seen in the inset image histogram (D). This is due to differences in spectral reflectance between the visible red $(0.65 \mathrm{~mm})$ and the near infrared $(0.85 \mathrm{~mm})$, as shown by example field spectra (E and F). NDVI time series from example grassland (G) and forest (H) pixels show clear differences in phenology. These differences are quantified by covariance of the image time series, providing the basis for mapping with Empirical Orthogonal Function (EOF) analysis. 
The studies referenced above have documented the difference in plant species composition between the forests and grasslands, as well as various aspects of the regional micrometeorology and ecohydrology. However, to our knowledge, neither the dynamics of the relationship between precipitation and phenology, nor the variability within ecozones have yet been comprehensively characterized in a spatiotemporally explicit way. This analysis of Jabal Dhofar thus serves as an example of the type of information that spatiotemporal analysis can contribute to the base of scientific knowledge obtained from more traditional ecological and hydrological methods.

\section{Materials and Methods}

\subsection{Field Observations}

Field reflectance spectra of rock and soil substrates, green and senescent vegetation, and clouds were collected using an ASD HandHeld2 field spectrometer (Figure 1E,F). These Visible through Near Infrared (VNIR) field spectra were used for a comparison of sub-meter scale reflectance of specific land covers with the aggregated reflectance measurements that were derived from the MODIS radiance observations. The details of this comparison are given by [40]. Land cover and vegetation type were field validated by the authors, with over 25,000 geotagged photographs and dashcam video of over $2500 \mathrm{~km}$ of driving and walking transects in February and March of 2016 and 2017. Field photos and spectra were used for scaling comparison and validation of meter-resolution (Quickbird, Worldview) and simultaneously acquired decameter-resolution (Landsat 8, Sentinel-2) satellite imagery-also described in detail by [40].

\subsection{Data and Preprocessing}

17 years of MODIS collection 6 near-daily surface reflectance imagery were acquired free of charge from the NASA REVERB data hub (https://reverb.echo.nasa.gov/). Data drop outs were excluded by flagging acquisitions with only partial coverage (swath edges) and those with large areas of missing data, yielding a total of 4236 images. Data corruption, indicated by anomalous reflectance values, was particularly obvious in three years $(2002,2011$, and 2016). These years were excluded from the calculation of the covariance matrices on which the EOF analysis was based. NDVI was computed at $250 \mathrm{~m}$ resolution and all of the images were stacked into one data cube.

\subsection{Spatiotemporal Characterization Methodology}

Analysis begins by applying the Principal Component (PC) transformation [41] to the NDVI image time series. The Principal Component transformation determines the dominant uncorrelated modes of variability (dimensions) that are present in the dataset. Each dimension is: (1) composed of a pair of associated spatial and temporal patterns, (2) uncorrelated with every other dimension, and (3) associated with some fraction of the total variance of the dataset. In the context of this work, the temporal patterns are referred to as Empirical Orthogonal Functions (EOFs) and the spatial patterns are referred to as Principal Components. The Principal Components can be conceptualized as spatial maps that depict the strength of each temporal EOF across the landscape.

High-dimensional remote sensing data can be explored using the concept of a feature space [42], in which relationships among the spectral bands are visualized using sets of complementary scatterplots. However, a multi-year time series of daily observations results in a temporal feature space too voluminous to be efficiently explored by simple comparison of scatterplots. The Principal Component transform addresses this problem. Principal Component dimensions provide an alternative coordinate system with which to examine the temporal feature space. This alternative coordinate system is mathematically optimized in important ways (orthogonal dimensions, rank-ordered by variance). Each pixel's Principal Component value along any given dimension of this new coordinate system corresponds to the extent to which that mode of variability contributes to that pixel's time series. The ranked partition of variance can sometimes provide a basis for the segregation of deterministic and 
stochastic dimensions [19], in many cases condensing the data into a small $(<10)$ number of physically meaningful patterns [23]. In such cases, the usable information that could potentially be obtained from pairwise examination of thousands of image time steps can be obtained by an investigation of a much smaller number of PC/EOF pairs.

\section{Results}

\subsection{Application to the Example Dataset}

In the case of our example time series, for both the Jabal Al Qara and the Jabal Al Qamar $>50 \%$ of the variance is present in the first three dimensions of the transformed data. Scatterplots showing the first three dimensions of the temporal feature space are shown in Figure 2. In these scatterplots, each point represents the time series of an image pixel (or many similar pixels), with the position determined by the relative contribution of the three dominant Principal Components. The geometrical relation between clusters of points in these scatterplots visually depicts the statistical similarity in cycles of cloud cover and vegetation phenology among distinct geographical pixels. In this way, the transformed temporal feature space efficiently characterizes the dominant spatiotemporal patterns in the dataset by showing them in an easily interpreted image. Interactive examination of these scatterplots can reveal important features of the dataset.

\section{Temporal Feature Space, Endmembers, and EOFs}

Figure 2A shows the Jabal Al Qara temporal feature space, endmembers, and associated low-order EOFs. The full 17-year time series of EOF 1 is shown in the upper right, while the median years of EOFs 1, 2, and 3 are shown in the lower right. EOF 1 can be understood to represent the average annual cycle and EOFs 2 and 3 can be considered as the most pervasive modulations of this cycle. These modulations principally alter the amplitude and timing of post-monsoon senescence. The geometrical structure of the temporal feature space is characterized by corners and relatively sharp edges. The pixel time series at the corners are the temporal endmembers (tEMs) of the feature space, representing the most statistically distinct temporal patterns. The continuum that is bounded by the endmembers is indicative of gradations among the extreme temporal patterns associated with endmember pixels at the corners and edges. The sharp edges suggest that most of the pixels in the image can be well represented by linear combinations of a relatively small number of endmember temporal patterns. As is typical with temporal feature spaces, the first Principal Component dimension represents the overall amplitude of the pixel time series.

Six distinct temporal endmembers are identifiable from the Jabal Al Qara feature space. The endmember time series are shown in the lower right, while their locations are shown on the Principal Component scatterplots. Most of these corners are most clearly visible from the projection showing dimensions 2 vs. 3 (upper right). Some corners are obscured from ready identification in the other projections, since they plot above or below the plane of the page and are therefore projected onto one another in a two-dimensional plot.

The two temporal endmembers that are most distinct in the dimension 1 vs. 2 scatterplot are the Null and Western Forest endmembers. The Null endmember corresponds to pixels with essentially no vegetation and is analogous to the origin of the feature space. The Western Forest, on the other hand, shows the highest amplitude phenology of all temporal patterns in Jabal Al Qara. The ready identification of the maximum and minimum amplitude phenological cycle using dimensions 1 and 2 is intuitive since the first dimension of an EOF transform corresponds to the temporal mean. These endmembers occupy positions that are indistinguishable at the bottom of the dimension 3 vs. 2 scatterplot, from which all of the other endmembers are identified. 

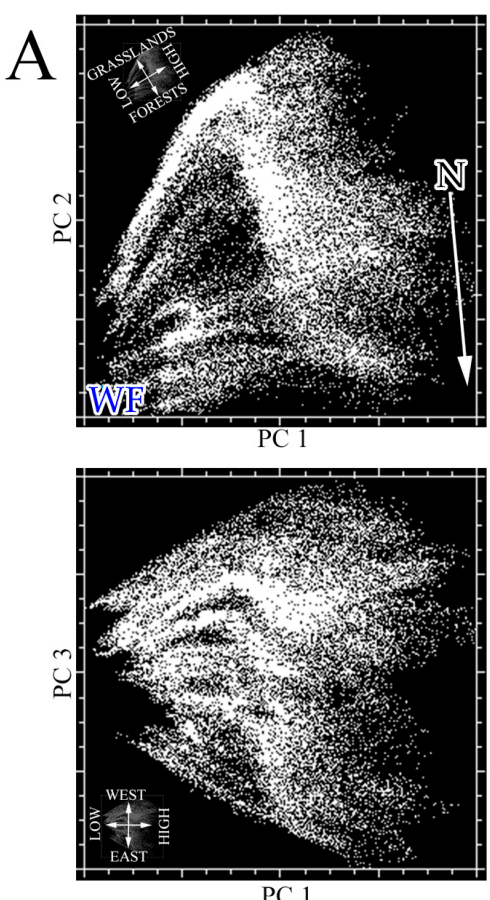

PC 1
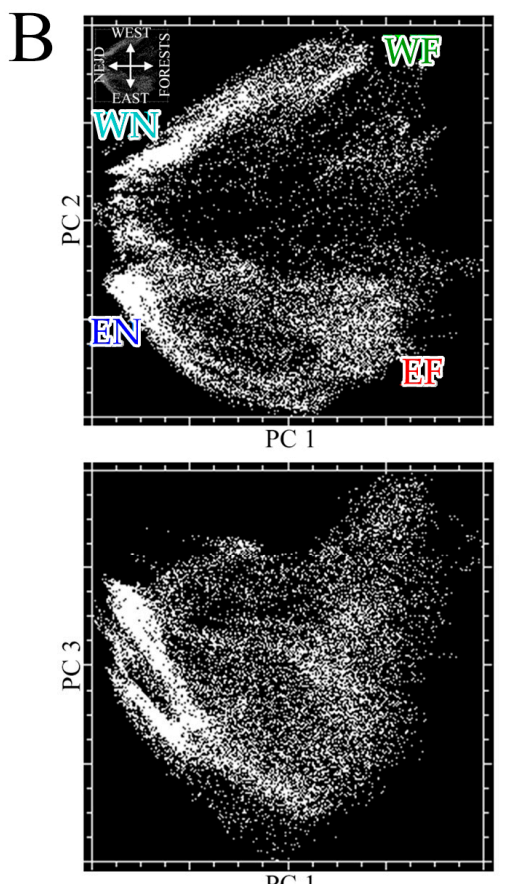
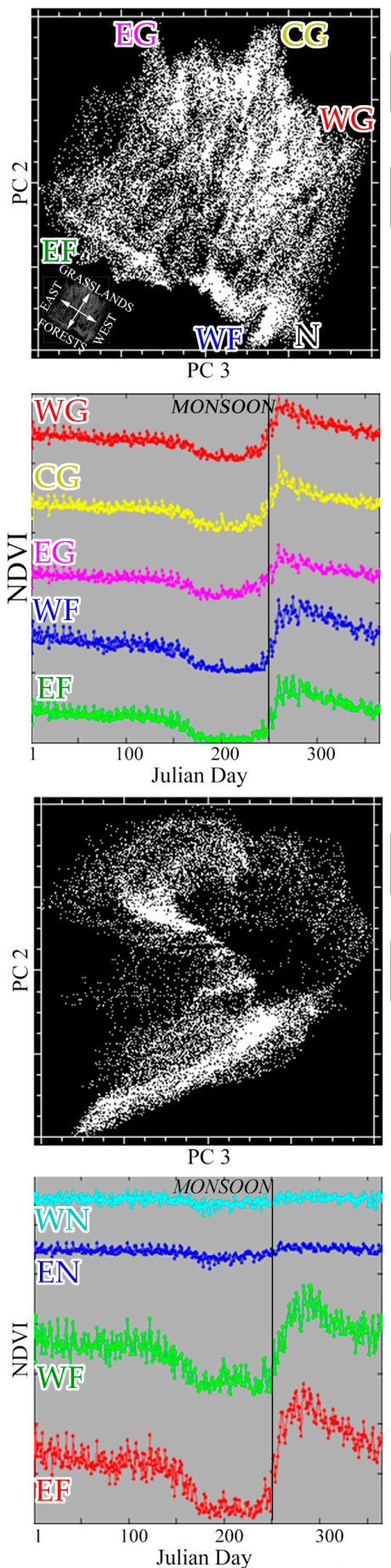

EOF $12000-2008$

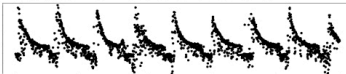

EOF 1 2008-2016

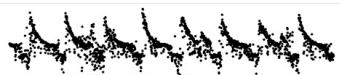

Median Year EOFs

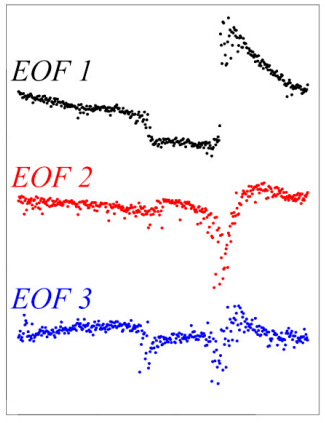

EOF 1 2000-2008

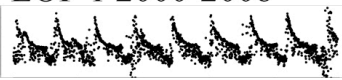

EOF 1 2008-2016

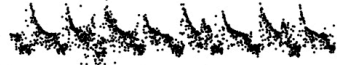

Median Year EOFs

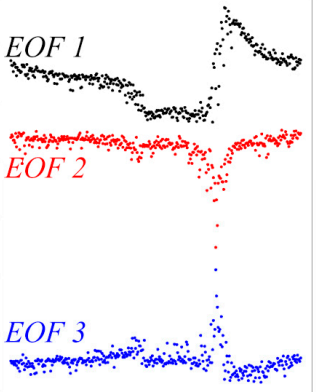

Figure 2. (A) Jabal Al Qara temporal feature space. PC 3 vs. 2 most clearly shows geographically meaningful partitioning. Eastern Grasslands (EG) and Forests (EF), left, grade to Western Grasslands (WG) and Forests (WF), right. Distinct Central Grasslands (CG) also exist, but no analogous central forests are present. WF overprints the Nejd (N) in the 3 vs. 2 projection. Endmember time series for 1001 pixel averages chosen from corresponding corners of the TFS are shown in lower right. (B) Jabal Al Qamar TFS. Geographic partitioning is again present, clearest in PC 1 vs. 2. Western Forests (WF) and Eastern Forests (EF) form nearly distinct clusters, with some intermediate gradation. Central forests are not sufficiently distinct to form an additional EM. Eastern Nejd (EN) and Western Nejd (WN) pixels grade toward a single null EM. The PC 3 vs. 2 projection forms a phase plane with Nejd pixels at the center and wadis on the circumference. EM time series for 101 pixel averages shown in lower right. Time series are vertically offset to emphasize synchrony of phenological responses to the monsoon; order of time series does not imply higher or lower values. EOFs for both regions shown on right side. 
The other temporal endmembers form clear corners on the scatterplot of dimensions 3 vs. 2. This combination of dimensions is fortuitous, as its geometry corresponds nearly directly to the geography of Jabal Al Qara. The forests and grasslands are clearly distinct from each other along an axis oblique to either of the individual dimensions. Furthermore, the eastern and western portions of the ranges are distinct from each other along an axis that is nearly perpendicular to the forest-grassland axis. This results in a boxy character to the dimension 3 vs. 2 scatterplot.

Individual forest subsystems are identifiable from the temporal feature space. Each curvilinear collection of pixels grading from the lower edge to the upper edge of the dimension 3 vs. 2 projection corresponds to a spatially coherent set of pixels grading from the base of an individual wadi up through higher elevations to the grasslands that immediately surround it. The full Jabal Al Qara region can thus be considered a composition of distinct phenologic subsystems that grade in a continuum from east to west. These individual wadi subsystems also radiate outward from the null endmember in the dimension 1 vs. 2 and 1 vs. 3 projections.

Samples of 1001 pixel time series were chosen from each of the endmember regions in the temporal feature space. In every case, these pixels cluster in geographic space to form endmember regions that are (nearly) spatially contiguous. The pixel time series for each region were then averaged together to form one mean endmember time series representative of that spatiotemporally distinct region. The five averages of these 5005-pixel time series concisely represent the spatiotemporal variability of all 33,729-pixel time series in the Jabal Al Qara subset of the NDVI image stack.

The time series for each of the Jabal Al Qara endmembers is shown in the lower right. For display purposes, the 17 years for each endmember time series were again averaged together to form a single representative year. While each statistically distinct region has a similar average annual cycle, variations in the amplitude of post-monsoon greenness and rate of senescence are clearly visible. These variations will be discussed below.

The temporal feature space for Jabal Al Qamar (Figure 2B) exhibits substantially less complexity than the temporal feature space for Jabal Al Qara. While the forests are again distinct, the minimal spatial extent of the grasslands results in the feature space grading directly from forested wadis into the sparsely vegetated Nejd. Two distinct Nejd corners are evident in the dimension 1 vs. 2 space. However, these are clearly grading toward a single Null endmember. These continua would have merged together if the spatial extent of the analysis had been expanded further inland. The time series for each of the Jabal Al Qamar endmembers, as well as the low-order EOFs, are shown in the lower right of Figure 2B.

Examination of the dimension 1 vs. 2 projection of the Jabal Al Qamar dataset also demonstrates much sharper spatial clustering than in the Jabal Al Qara. While a continuum does exist between the eastern and western forests of Jabal Al Qamar, the transition zone between them is narrower and more abrupt than in Jabal Al Qara.

\subsection{Mapping Distinct Spatiotemporal Patterns}

The continuum of temporal patterns visually evident in the temporal feature space can be geographically represented with a temporal mixture model (TMM). Temporal mixture models represent each pixel time series as a linear combination of temporal endmember time series [43]. The temporal mixture model can be considered a linear transformation of the data from statistically derived basis functions (EOFs) to physically meaningful basis functions (endmembers). This transformation allows us to base our interpretation of the temporal patterns in each pixel time series on physically meaningful processes rather than statistically derived patterns alone [23].

Temporal mixture models are generated by inversion of a simple set of mixing equations of the following form. Using $n$ total endmembers, for each pixel:

$$
X_{t_{i}}=F_{E M 1} E_{E M 1, t_{i}}+F_{E M 2} E_{E M 2, t_{i}}+\ldots+F_{E M n} E_{E M n, t_{i}}+\varepsilon
$$


where $X_{t i}$ is the NDVI at a given pixel at time $i, F_{E M(1 \ldots n)}$ is the relative contribution of endmember 1 $(2, \ldots n)$ to that pixel, and $\varepsilon$ is the model misfit. $\varepsilon$ can be minimized using ordinary or constrained least squares.

For the example dataset, we generate temporal mixture models for Jabal Al Qara and Jabal Al Qamar using the endmember ensembles that were identified from each feature space. Each pixel time series is thus characterized by a linear combination of six (or four) endmembers, plus error. For each of these models, $95 \%$ of all root-mean-square pixel misfits were below 5\%. Figure 3 shows maps of these temporal mixture models. In each map, primary colors (Red/Green/Blue or Cyan/Magenta/Yellow) represent the weights of three of the endmembers. The fractions are linearly displayed in the range of 0 to 1 for each endmember. For instance, in Panel A, a pixel in the western forests of Jabal Al Qara would appear as saturated red (100\% red, $0 \%$ green, $0 \%$ blue), while a more centrally located forest pixel could appear as yellow (50\% red, 50\% green, $0 \%$ blue). In contrast, a Jabal Al Qara grassland pixel would appear as black ( $0 \%$ red, $0 \%$ green, $0 \%$ blue) in Panel A since no grassland endmembers are represented in that map, but bright in Panel B. In each panel, the locations of the endmember pixels that were selected from the temporal feature space are outlined in white.

The locations of endmember pixels, and the spatial distribution of endmember temporal patterns in non-endmember locations, indicate strong biogeophysical clustering with examples of both gradual and abrupt transitions across the landscape. This directly emerges from the spatiotemporal structure of the data-without any prescribed assumptions about regional geography, climate, or ecology. The consistency in geographic location of the endmember pixels selected from the apexes of the temporal feature space is an important result because it reinforces the physical meaning in temporal feature space structure, providing clear evidence that the temporal patterns are related to geographic factors like elevation, slope, and coastal proximity. The spatial coherence of the endmember pixels was not imposed a priori, and is not required by the analysis.

The clustering of endmember locations is particularly prominent in the western forests of Jabal Al Qara (Panel A, red). The most distinct temporal patterns clearly track individual wadi subsystems and do not include the grasslands separating them. The eastern forests (green) also form a spatially coherent cluster distinct from the western forests, with little mixing between the two. Regions with minimal vegetation (blue) are most extensive in the Nejd, but also include barren portions of the coastal plain. In contrast, the phenology of the Jabal Al Qara grasslands (Panel B) shows a remarkably smooth gradation between distinct western (magenta), central (yellow), and eastern (cyan) patterns. Notably, the central Jabal Al Qara grasslands emerge as phenologically distinct and not a simple mixture of the eastern and western grassland endmembers.

Jabal Al Qamar (Panel C) phenology also shows east-west differentiation. The forests are clearly broken into eastern and western zones, divided by a sharp gradient. Spatial mixing in Jabal Al Qamar is likely minimized by the rugged topography that physically divides the range. While the Nejd also shows east-west variation in space, the temporal patterns of each endmember region (shown below) are so similar to each other, and contain so little signal, that we do not conclude any significant phenological distinction between the two regions. 

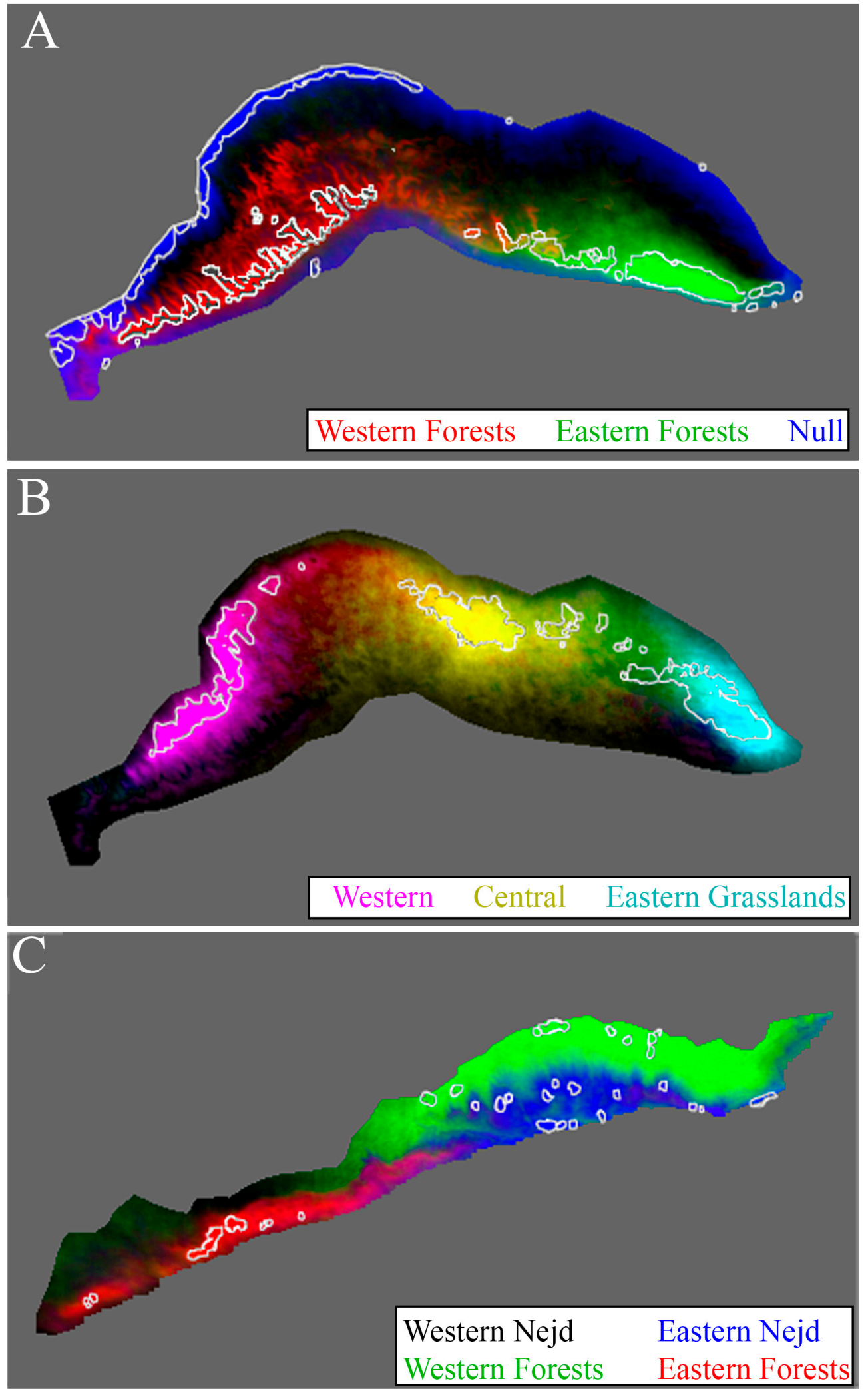

Figure 3. Temporal affinity maps and endmember regions for Jabal Al Qara and Jabal Al Qamar. Forest vegetation phenology in Jabal Al Qara (A) is largely divided between distinct east and west regions with some mixing in the center of the range. Grasslands in Jabal Al Qara (B) exist on a continuum with higher maximum greenness and slower senescence in the west than the east. Forest phenology in Jabal Al Qamar (C) is also divided by longitude into two distinct clusters, with minimal mixing in the central portion of the range. While both Nejd EMs in Jabal Al Qara are essentially null, enough statistical difference in patterns of cloud cover exists to separate them into two distinct groups. All colors are stretched linearly from $0 \%$ to $100 \%$ affinity. EM locations are outlined in gray. 


\subsection{Time Series Comparison of Distinct Spatiotemporal Patterns}

Endmember time series provide temporal information that is complementary to the spatial patterns that are shown above. For the example dataset, we present endmember time series as averages of the pixels within endmember regions that were identified from the temporal feature space in Figure 2 and are outlined in white in Figure 3. We display the median, along with the first and third quartiles, of the annual cycle of each endmember region in order to demonstrate both overall phenology and interannual variability in each distinct endmember region (Figures 4 and 5). Individual years are examined later using the full 17-year time series for these same endmember regions (Figures 6 and 7).

Examination of Jabal Al Qara endmember time series (Figure 4) reveals both common behavior and substantial differences among regions. The monsoon dominates all endmembers, with NDVI from mid-June through mid-September consistently below the global mean (thin horizontal lines) for all endmembers, including the Nejd. As explained above, this results from the near-zero NDVI of clouds versus the small but positive NDVI of bare soil, regolith, and NPV. Grasslands in Jabal Al Qara are clearly differentiated from forests on the basis of amplitude and rate of senescence of post-monsoon greenness. Regardless of longitude, forests generally reach higher peak NDVI and take longer to senesce than grasslands. During the monsoon, forests also generally have longer, less interrupted cloud cover than grasslands. Additionally, clear longitudinal signals are present in both forests and grasslands. Greening is observed to be stronger in the west and weaker in the east. It is the combination of the east-to-west and forest-to-grassland gradients that gives the temporal feature space its structure.

The forests of Jabal Al Qamar (Figure 5) also demonstrate an east-west gradient in phenological amplitude, but in the opposite direction. The observation that these gradients converge in the unvegetated, high elevation region between the two ranges is interesting, and, to our knowledge, a novel contribution to the biophysical geography of the area. In addition to the longitudinal gradient, both the eastern and western forests of Jabal Al Qamar show prominent but variable early greening.

Figures 6 and 7 show the full 17-year time series for spatial averages of each endmember region. The years with obvious data quality issues (2002, 2011, and 2016) are included in these figures to illustrate the character of the dataset. As in Figure 4, the western grasslands of Jabal Al Qara (magenta) are consistently greener longer than the eastern grasslands (cyan). Central grasslands (yellow) generally lie between. Some years show prominent longitudinal differences, while for other years, all three grassland regions behave nearly identically. The longitudinal gradient is even more pronounced for forests than grasslands. Much of the year-to-year variability occurs coherently across the endmember regions. Some years are substantially greener than others in every region, and in some years the greening lasts longer than others (e.g., 2004 vs. 2005). However, in other years, greening occurs in a spatially variable sense and is confined to individual endmembers or subsets of endmembers (e.g., western grasslands are substantially greener in 2009 than 2010, but eastern and central grasslands are not). Additionally, the early parts of 2005, 2007, and 2010 show prominent early greening (or regreening) in the forests of both the ranges. This result was unexpected and, to our knowledge, has not been previously documented.

In contrast, time series of the east and west Jabal Al Qamar forests (Figure 7) show prominent differences from the east and west Jabal Al Qara forests. One aspect of this difference is the nature of cloud cover. Persistent cloud cover has substantially shorter duration in Jabal Al Qamar than Jabal Al Qara. However, much more day-to-day variability in post-monsoon cloud cover is also present in the Jabal Al Qamar than Jabal Al Qara. Field observations confirmed this difference in post-monsoon cloud cover. Finally, the greening of vegetation in Jabal Al Qamar endmember regions is more intense, more persistent, and more frequently observed out of season than in Jabal Al Qara endmember regions. 

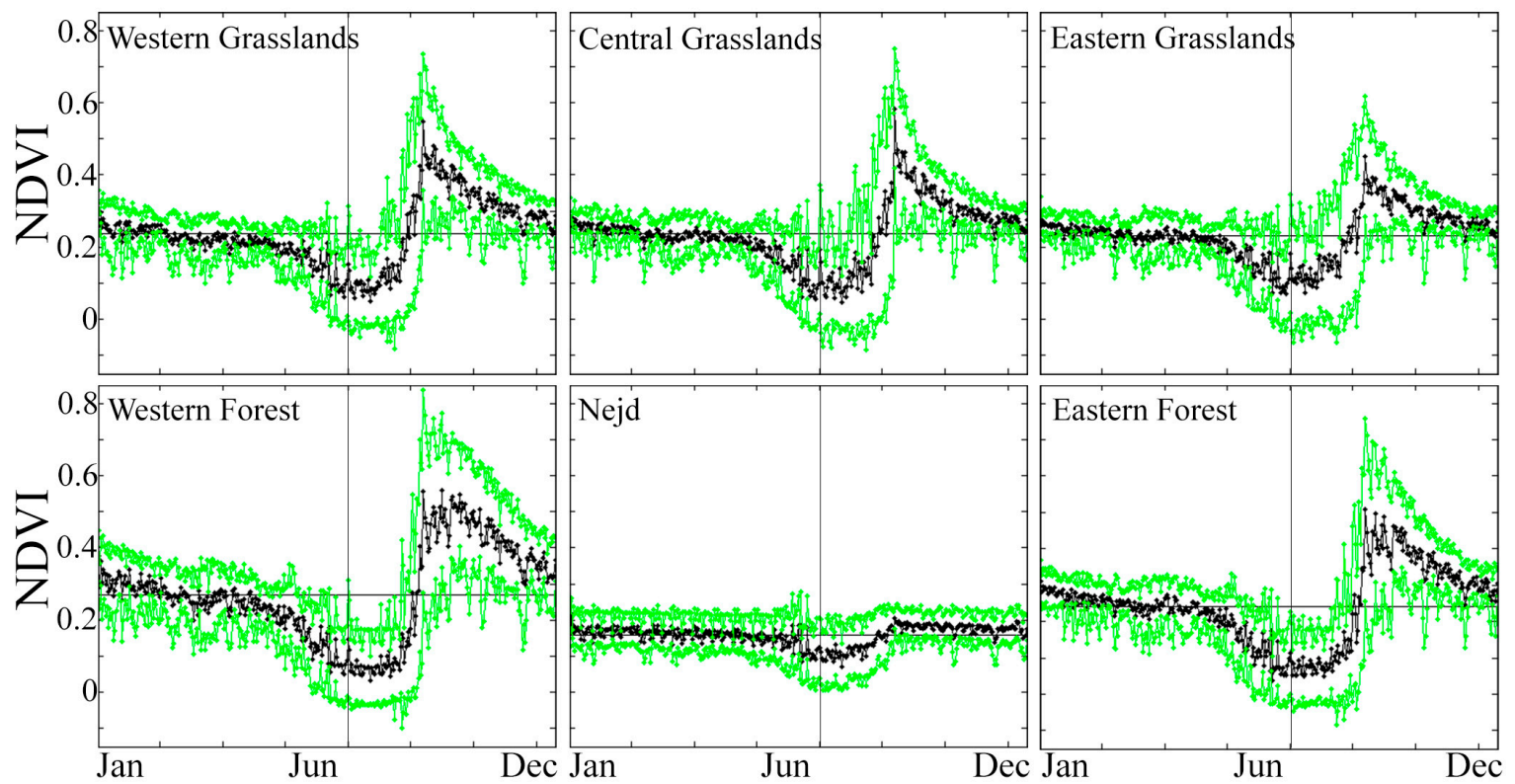

Figure 4. Jabal Al Qara EM annual cycle. Median (black) and 1st \& 3rd quartiles (green) for each endmember region computed over 2000-2017. Forests reach higher maximum NDVI values and senesce slower than grasslands. Western regions of both grasslands and forests senesce slower and show more variability than eastern regions. Clouds clear earlier and are less consistent over grasslands than forests. Clouds are more consistent in the west than the east. On average, monsoon onset is more gradual than termination, especially in forests. Nejd values are low year-round, with a minor but consistent annual cycle due to solar geometry. Annual medians for each EM region shown as thin horizontal lines; July 1 (Julian Day 182) shown as a thin vertical line for visual reference.

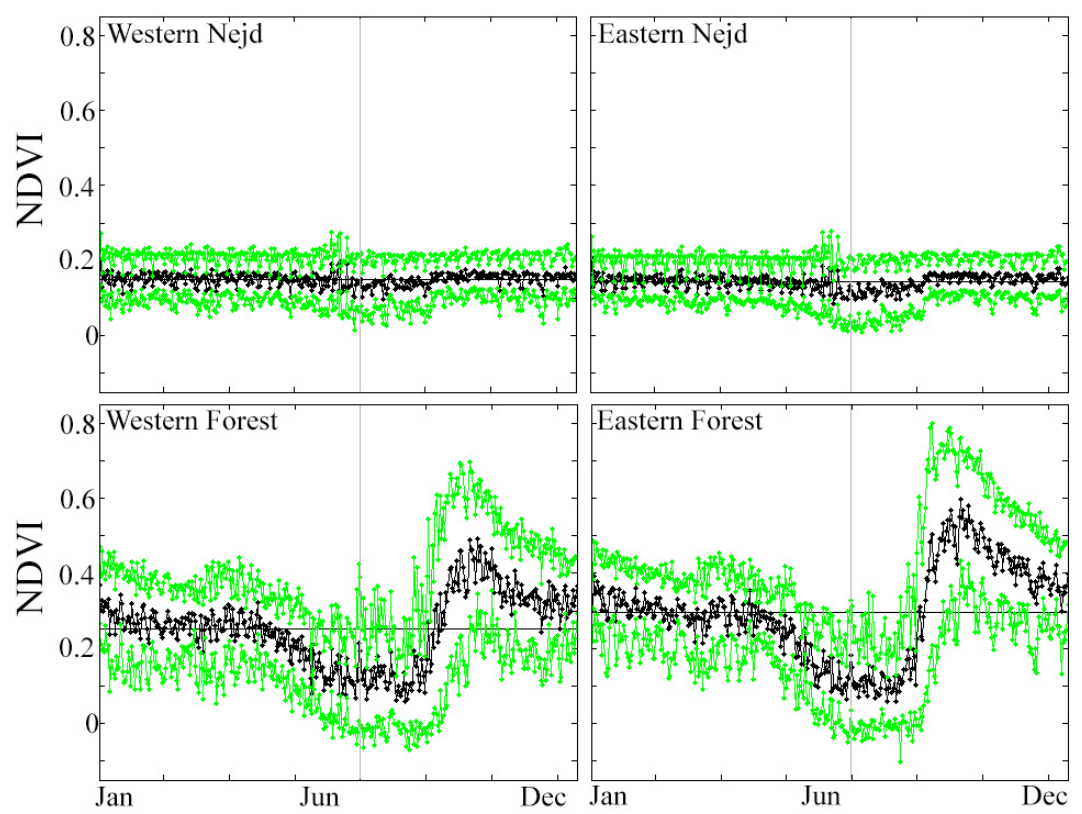

Figure 5. Jabal Al Qamar EM annual cycle. Median (black) and 1st \& 3rd quartiles (green) for each EM region computed over the period 2000-2017. Opposite from Jabal Al Qara, forests in Jabal Al Qamar generally have higher maximum values and slower senescence in the east than the west. In some wet years, the regreening post-monsoon is prominent in both western and eastern endmember time series. Similar to Jabal Al Qara, onset of the monsoon is more gradual than termination. Nejd values are low year-round with barely visible east-west variations, predominantly due to variations in monsoon cloud cover. The solar illumination cycle is also faintly present. Annual medians for each EM region shown as thin horizontal lines July 1 (Julian Day 182) shown as a thin vertical line for visual reference. 

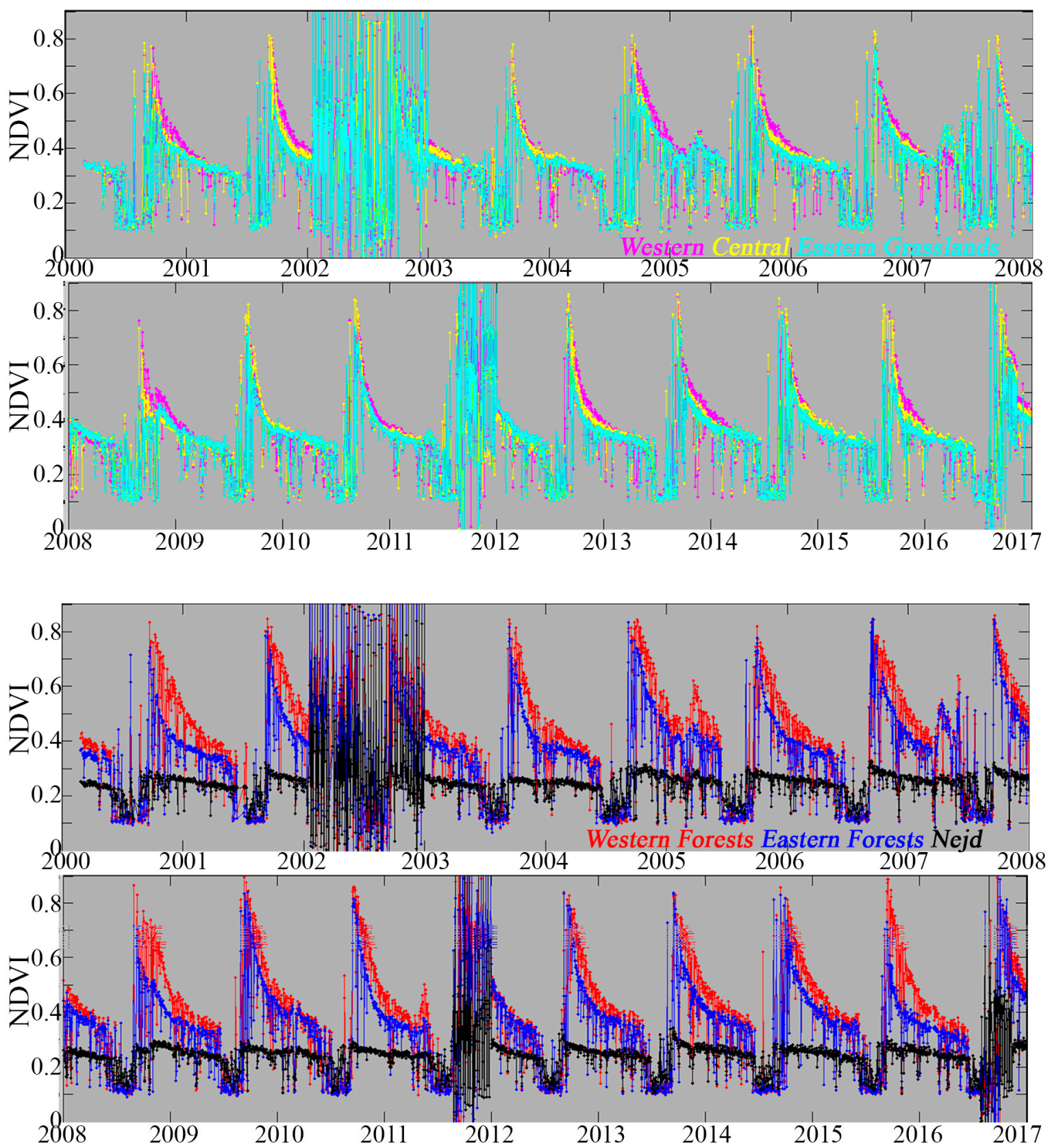

Figure 6. Full 18-year Jabal Al Qara EM time series. Each curve is the spatial average of the 1001 pixels that comprise each EM region. Substantial variability is observed among and within EMs. Grasslands vary from year to year in maximum greenness, rate of senescence, and relative similarity of western, central, and eastern regions. Some years show post-monsoon regreening in one or both of the forest EM regions, but most years do not. Years with both strong and weak greening in both forests and grasslands are present at both the beginning and end of the time series. No clear trend is visually evident in duration or timing of monsoon, maximum greenness, or rate of senescence of any EM. 

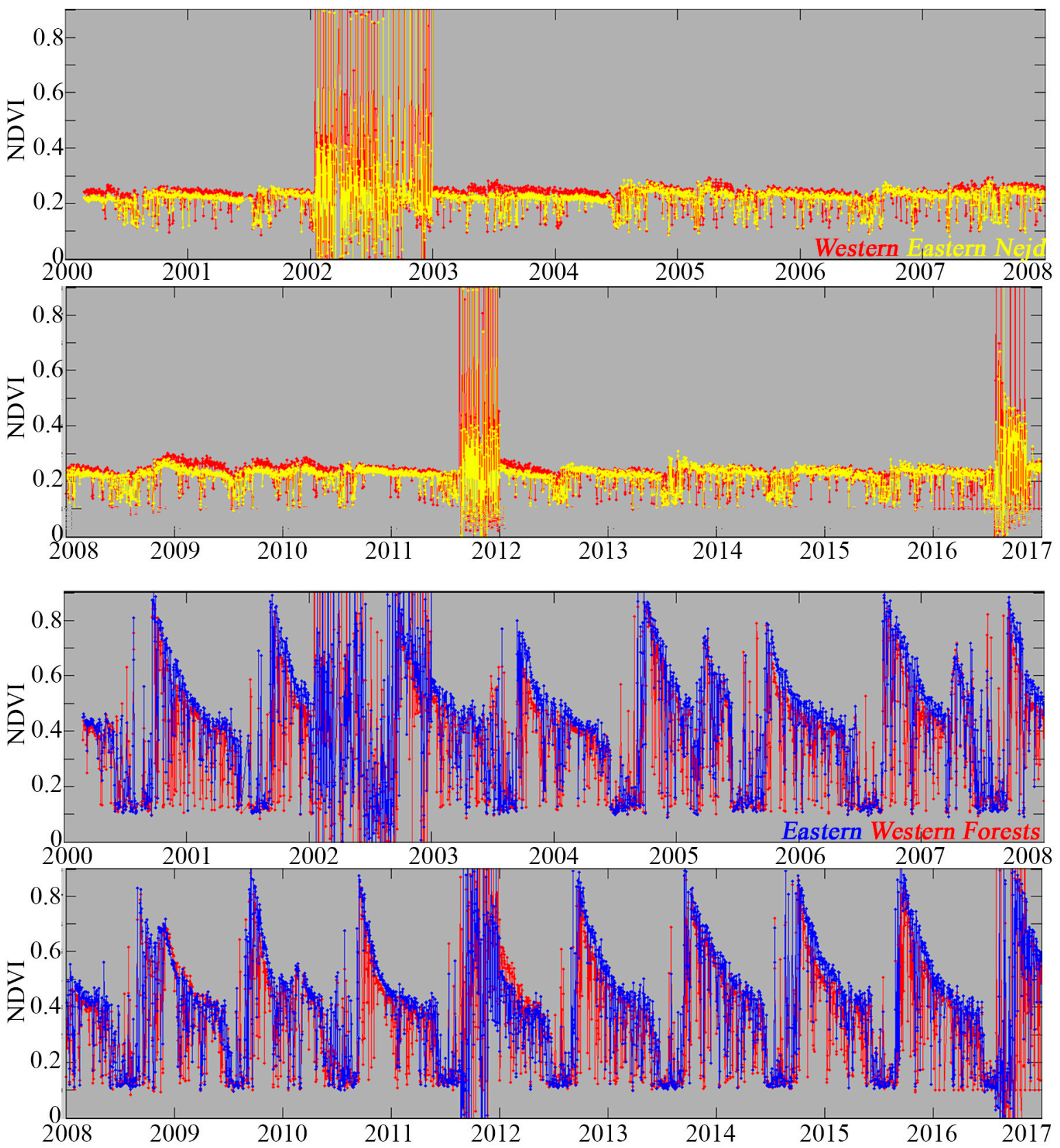

Figure 7. Full 18-year Jabal Al Qamar EM time series. Each curve is the spatial average of the 101 pixels that comprise each EM region. As with Jabal Al Qara, substantial variability is observed among and within EMs. Eastern forests are generally greener than western forests. Post-monsoon regreening appears more frequent and more intense in Jabal Al Qamar than Jabal Al Qara. As in Jabal Al Qara, years with both strong and weak greening of Jabal Al Qamar are present at the beginning and end of the time series. Again, no clear trend in any EM time series is evident. Minor but consistent differences are present between the eastern and western Nejd, but the values of NDVI involved are so low that we do not attempt to ascribe physical meaning to these differences.

\subsection{Historical Trends}

Spatial averaging of pixel time series within endmember regions can enhance the detection of interannual trends over the duration of the satellite image archive. Because time series within each endmember region are selected on the basis of their statistical cosimilarity (and their dissimilarity from pixels in the other endmember regions), the benefits of averaging coherent time series are maximized, while the confounding effects of introducing time series with phase differences into the average are 
minimized. This approach simultaneously 1) reduces the noise present in single pixel time series, and 2) allows for the preservation of geographic differences in phenology. Segregating time series by phenologic phase is particularly important for analysis of historical trends, because relative phase differences can bias estimation of interannual trends if averaged together.

We approach the question of historical trend detection using anniversary images (collected on the same Julian day each year) from dates with the fewest number of cloudy acquisitions across the 17-year time series. We do this for three 30-day windows after the end of the monsoon (Figure 8). Anniversary images are required due to the natural interannual variability in timing and amplitude of the monsoon-phenological system seen in Figures 4-7. For an interannual trend to be detected, its magnitude must be at least as large as this natural variability. Introducing even small changes in sampling date has the potential to bias multiyear statistical analysis. Year-to-year changes in sampling date are unavoidable with products using the 8- or 16-day MODIS compositing process.

We choose the months after the monsoon in order to optimize the trade-off between amplitude of NDVI signal and lower frequency of cloud cover. However, to avoid introducing bias by choosing an unrepresentative Julian Day, we also show full calendar plots for each endmember region. Every cell of these $17 \times 366$ matrices represents one day of the time series. Each row is a year and each column is a Julian Day. Spatial average NDVI of each set of endmember pixels is represented as grayscale brightness. Brighter cells have higher NDVI. These calendar plots have the advantage of displaying the entire image time series for each endmember region. Obvious trends in monsoon or vegetation phenology should be apparent as vertical gradations in the lightness of these calendar plots. Less obvious trends may emerge from statistical analysis of the anniversary date time series. The anniversary plots that are shown to the left of the calendar plots are simply column profiles of the calendar plots with the fewest data drop-outs or cloud cover.

The subregional analyses reveal no consistent trends in the onset or duration of the monsoon, nor any interannual trend in overall vegetation abundance. Both parametric linear regression and non-parametric Mann-Kendall tests were applied to each time series. Of the 21 anniversary date-endmember region combinations examined here, only one shows a trend significant at the $90 \%$ or $95 \%$ confidence levels, and none show significant trends at the $99 \%$ confidence level. The same number of significant trends is found for both parametric and non-parametric approaches, with the exception of the loss of $95 \%$ significance of the one observed trend when using the Mann-Kendall approach. If real, this single trend would imply a very small (0.02 NDVI / year) progressive increase of forest vegetation cover in the eastern Jabal Al Qamar. However, we do not ascribe any physical meaning to this trend, because the small amplitude of the trend pushes the detection limit of the NDVI metric beyond our confidence. Furthermore, on average, an examination of 20 time series will yield one with a significant trend at $95 \%$ confidence based on random chance alone.

The lack of any apparent trend in the daily MODIS NDVI contradicts the conclusion of a recently published study [44] which infers widescale land degradation throughout Jabal Dhofar from an analysis of 16-day MODIS NDVI composite imagery. We attribute this disparity, at least in part, to the difference between daily and composite MODIS data, as discussed below. 


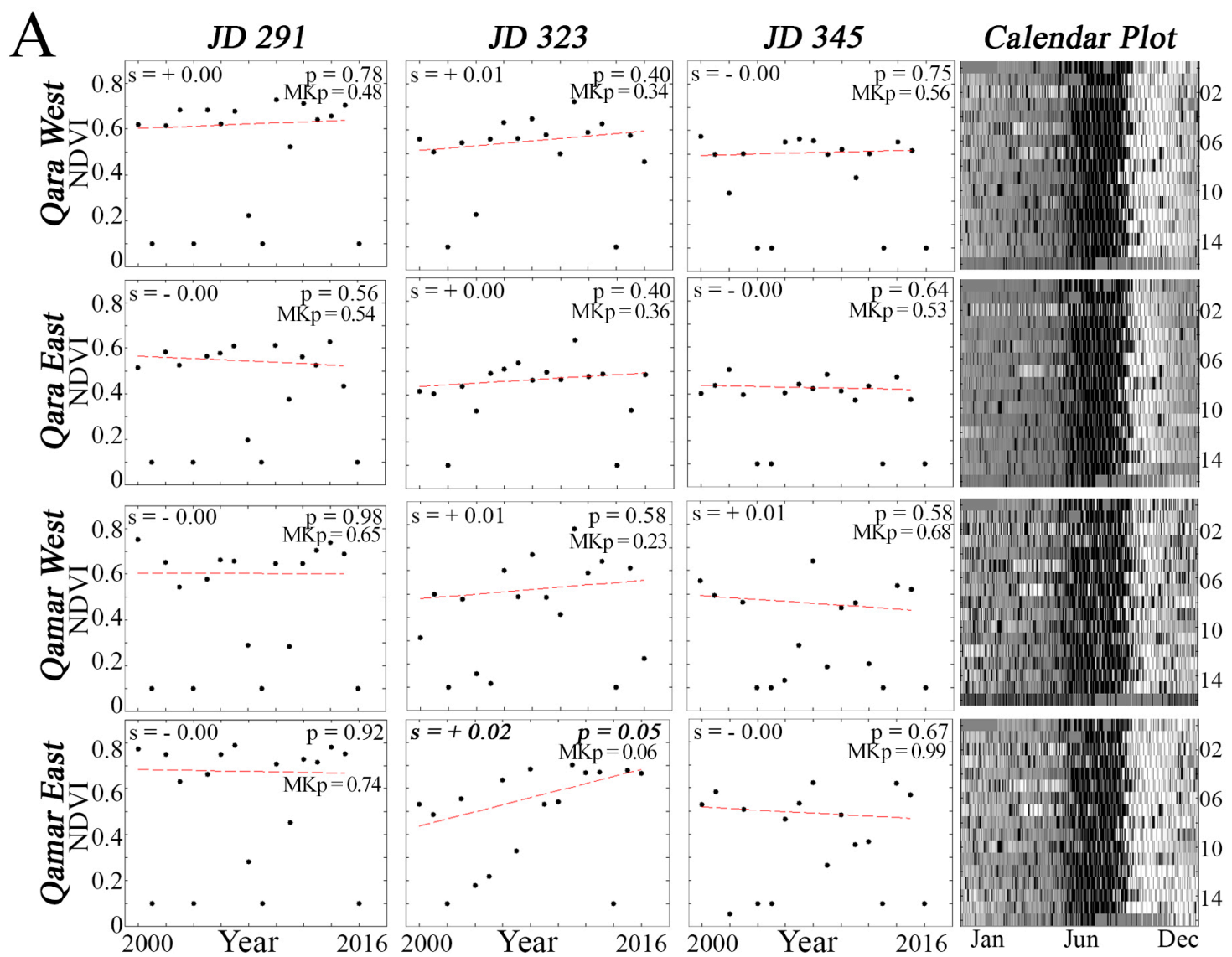

B

Figure 8. Interannual trends in vegetation cover. Panel A shows forests and Panel B shows grasslands. The Julian Day with the fewest missed or cloudy (NDVI < 0.1) observations was chosen for three 30-day post-monsoon time windows. Anniversary time series for spatial averages of each region are plotted, along with best fit linear trends. P values for both linear regression and 2-sided non-parametric Mann-Kendall (MKp) shown. Only one trend is significant to $95 \%$ confidence, but the slope is small (0.02), the number of years in the time series is modest, some early years of the time series appear affected by cloud contamination, and no trend is apparent in that EM either earlier or later in the decade. We do not ascribe physical significance to this trend without further evidence. 


\section{Discussion}

\subsection{Comparison to Spatiotemporal Analysis in other Environments}

In monsoonal environments, pervasive cloud cover seasonally obscures Earth-leaving radiance. This results in a consistent, recurrent transition in the information content that is present in optical satellite image data. When clouds are absent, satellite imaging observes the land surface; when clouds are present, the atmosphere is observed. This seasonality, combined with the relationship between the timing and extent of the monsoon cloud cover and phenology, creates a novel special case of the general spatiotemporal analysis problem. This special case may be of particular interest to scientific and lay audiences alike, given the number of monsoonal landscapes with particularly important environmental and/or socioeconomic properties.

The spatiotemporal analysis approach presented here leverages the bivariate (atmosphere + biosphere) properties of monsoon environments using time series of a single land surface parameter (NDVI). However, in other cases, it could be reasonable to approach the problem from the perspective of parallel analysis of two related land surface parameters. For example, this second approach has been taken by the recent study of [45] for the purposes of mapping and monitoring rice agriculture. The two variables of interest in the rice study were vegetation abundance and land surface temperature at the spatial and temporal resolution of the Landsat 8 optical and thermal sensors. In contrast to the results presented here, the finer spatial resolution of the Landsat sensors oversampled the fields in the agricultural study area, but the coarser temporal resolution undersampled day-to-day phenological variations in the timing of planting and harvest. When viewed together, these two studies provide complementary cases illustrating the results of applying this spatiotemporal analysis methodology to datasets with variable spatial and temporal resolutions. This extends previous work from univariate studies, such as those that are presented in [43,46], as well as the examples discussed in [23]. In addition, we note that the methodology proposed here can complement rather than replace time series methods such as those proposed by [47-49] and in situ observations, such as those proposed by [50,51]. For example, the EOF characterization of temporal endmembers can inform the selection of functional forms to be used in fitting time series, as well as the identification of sites of interest for focused field investigation.

\subsection{Implications for Jabal Dhofar}

Results from the example study area illustrate the type of information to be expected from the spatiotemporal analysis approach. In Dhofar, the location of the temporal endmembers in geographic space is consistent with expectations given local expertise and field observations of spatial variability in the relative strength of the monsoon. The clustering of individual wadi subsystems into relatively compact, curvilinear manifolds within the temporal feature space is highly suggestive that consistent differences in climate and phenology exist among many wadis. The observation that wadis which are adjacent in geographic space are represented by manifolds which are adjacent in the temporal feature space suggests gradual spatial gradients in both monsoon strength and phenological intensity across the study area. These gradients are predominantly oriented east-to-west in both Jabal Al Qara and Jabal Al Qamar, although with opposite polarity. Within-wadi variability can largely be explained by topographic gradients in slope and elevation. This agreement between spatial patterns of endmember affinity and known features of the physical geography of Jabal Dhofar provides strong evidence that the spatiotemporal patterns that are identified from the feature space are biogeophysically meaningful.

Despite the lack of any observed historical trends in the MODIS time series, our field observations confirm extensive overgrazing throughout the study area in the form of physical damage to native trees and shrubs, the nearly complete absence of ungrazed grasses, and the spatial extent of invasive plant species indicative of ecological succession. However, we see no evidence that this degradation is consistently captured in the MODIS record as degradation found by [44]. In our view, the absence of any appreciable trend in the either the anniversary time series or the full, near-daily 17-year calendar 
plots that are shown in Figure 8 provides stronger evidence than can be obtained from analysis of MODIS composite time series, particularly because of the potential for the introduction of artifacts by the compositing process [52].

Importantly, we do not interpret our results as contradicting claims of overgrazing itself. Rather, we observe that the effects of overgrazing are apparently masked by concurrent senescence of post-monsoon vegetation, interannual variability of phenology related to variability in the timing and extent of the monsoon, and the inability of multispectral sensors to discriminate between the plant species. The limitations of hectometer satellite imaging in terms of pixel footprint, terrain correction, BRDF compensation, and subpixel cloud cover are substantial, especially in areas like Dhofar with substantial relief and a relatively small geographic extent. While we cannot state with certainty, we suggest that the discrepancy between our results and those of [44] may be partially explained by some or all of the following factors: 1) aliasing of interannual phenological variability by the 16-day MODIS compositing process, 2) inaccuracies introduced by the presumption of sinusoidal basis functions, and 3) noise that is present in pixel-level time series, which is partially reduced by using the spatial mean of all pixels in the endmember regions. In addition, further analysis using $30 \mathrm{~m}$ Landsat imagery over a longer baseline (1985-2017) revealed relatively few isolated areas with detectable loss of forest cover [40].

It is further important to note that the presence or absence of historical trends does not necessarily have straightforward implications for the future behavior of a complex system. This is especially noteworthy in a case like Dhofar, where degradation is observed in the field, but is not captured by the limited spatial, spectral, and temporal resolution of the multispectral satellite archive. In addition, in many landscapes, the relationship between cloud cover and vegetation may not be stationary. Non-stationarities in climate-vegetation coupling can be abrupt or gradual. This is especially likely in cases where the species composition of vegetation communities changes appreciably through time (e.g., invasive species), where pests cause species-selective mortality (e.g., bark beetle infestation in conifers), or where critical weather/climate transitions are reached (severe drought or frost). All of these potential causes of nonstationarity are particularly likely in ecosystems that are made susceptible by degradation, such as that of Jabal Dhofar. The EOF analysis that is presented here-like any characterization based on historical data alone-has no power to predict such transitions in the future.

Finally, the inferred link between cloud cover and vegetation phenology suggested by this analysis relies on soil moisture. While some measurements of soil moisture have been made in the Dhofar study area [30], many fundamental questions related to the inferred cloud cover-soil moisture-vegetation abundance causal mechanism still require field validation. In particular, continuous in situ measurement of soil moisture at sites controlled to have a minimum of disturbance from humans or livestock could then be compared to ongoing near-daily observations of cloud cover and vegetation abundance, as used in this study. One hypothesis predicts that soil moisture should increase with the onset of monsoon cloud cover and begin to subsequently decrease when the clouds clear and evapotranspiration increases. Regions with higher soil moisture would be expected to have more frequent or longer duration cloud cover, as well as more abundant vegetation and/or slower rates of senescence. As this investigation would only strictly require accurate relative (not absolute) measurement of soil moisture, a network of relatively inexpensive frequency-domain reflectometry probes could be used.

\subsection{Potential Application to Evapotranspiration}

Evapotranspiration (ET; evaporation + transpiration) plays an important role in a wide range of biogeophysical processes [53]. In arid environments like Dhofar, water availability is of particular biological importance. A wide range of models exist to estimate ET from in situ and remotely sensed data, and improving satellite-based ET measurements is a major focus of ongoing work in the discipline [54]. Applying the spatiotemporal analysis methods that are developed here to time series of spatially explicit ET estimates, such as those expected from the recent ECOSTRESS mission [55], 
could provide additional insight into monsoonal landscapes. This could be especially informative when viewed from the spectral mixture modeling perspective, as proposed by [56].

\section{Conclusions}

We present a simple method to characterize the spatiotemporal dynamics of cloud cover and vegetation phenology for monsoonal landscapes. The method first uses the Principal Component transform to distill the full spatiotemporal complexity of an image time series into a small number of dominant modes of variability, and it then uses the temporal feature space of the low order Principal Components to identify the most distinctive and physically meaningful temporal patterns present in the data. The most statistically extreme temporal endmember patterns are identified. Pixel time series from the rest of the image can be represented as linear combinations of these endmember time series. The inversion of a linear temporal mixture model generates maps of the most statistically distinct and physically meaningful spatiotemporal patterns. Trends in individual regions may be investigated with greater accuracy than analyses relying on either pixelwise or total spatial averaging methods, because statistically similar pixel time series are selectively grouped together so that their common phenologies combine in phase to suppress noise and amplify any spatial or temporal differences among regions. Because of the reflectance signatures of green vegetation, non-photosynthetic vegetation, soil, and clouds, both cloud cover and vegetation phenology can be simultaneously quantified using an image time series of a single variable (NDVI). Near-daily imagery can be used to avoid the temporal aliasing inherent in the commonly used 8- and 16-day MODIS vegetation index composites.

To illustrate the method, we apply it to an example time series featuring 17 years of daily MODIS NDVI imagery of Jabal Dhofar, southern Oman. The daily MODIS data captures rapid greening and rate-varying senescence of post-monsoon vegetation as well as spatial transitions between grasslands and forests. Characterization reveals five distinct spatiotemporal phenologies in Jabal Al Qara and two in Jabal Al Qamar, with clear gradients associated with both topography (between forests and grasslands) and longitude (between east and west) in each range. The distribution of these endmember patterns is spatially coherent, which indicates that the structure of the temporal feature space contains meaningful geographic variations in cloud cover and vegetation phenology. We find substantial interannual variability in cloud cover and vegetation phenology in every endmember region. Only one minor (+0.02 NDVI/year) statistically significant trend is observed in the 21 anniversary date-endmember region combinations examined. Moving forward, the global coverage, near-daily temporal resolution, and 18+ year record of MODIS data allows for this method to be applied to characterize the variability and trends in monsoonal vegetation anywhere on Earth.

Author Contributions: Conceptualization, D.S. and C.S.; methodology, D.S. and C.S.; validation, D.S., C.S., A.S. and A.K.; formal analysis, D.S.; investigation, D.S., C.S., A.S. and A.K.; writing-original draft preparation, D.S.; writing-review and editing, D.S., C.S., A.S. and A.K.; funding acquisition, C.S., A.S. and A.K.

Funding: Work done by D. Sousa was conducted with Government support under FA9550-11-C-0028 and awarded by the Department of Defense, Air Force Office of Scientific Research, National Defense Science and Engineering Graduate (NDSEG) Fellowship, 32 CFR 168a. CS was supported by the NASA MultiSensor Land Imaging program (grant NNX15AT65G). Fieldwork was supported by the Sultan Qaboos Cultural Center in the form of an SQCC Research Fellowship to C. Small.

Acknowledgments: The authors thank two anonymous reviewers and an anonymous academic editor for constructive comments which helped improved the manuscript. D. Sousa thanks F. Sousa III for innumerable illuminating conversations.

Conflicts of Interest: The authors declare no conflict of interest.

\section{References}

1. $\quad$ Fein, J.S.; Stephens, P.L. Monsoons; Wiley: Hoboken, NY, USA, 1987; ISBN 0471874167.

2. Wright, S.J. Phenological Responses to Seasonality in Tropical Forest Plants. In Tropical Forest Plant Ecophysiology; Springer: Boston, MA, USA, 1996; pp. 440-460. 
3. Raghubanshi, A.S.; Srivastava, S.C.; Singh, R.S.; Singh, J.S. Nutrient release in leaf litter. Nature 1990, 346, 227. [CrossRef]

4. Lodge, D.J.; McDowell, W.H.; McSwiney, C.P. The importance of nutrient pulses in tropical forests. Trends Ecol. Evol. 1994, 9, 384-387. [CrossRef]

5. Rudgers, J.A.; Chung, Y.A.; Maurer, G.E.; Moore, D.I.; Muldavin, E.H.; Litvak, M.E.; Collins, S.L. Climate sensitivity functions and net primary production: A framework for incorporating climate mean and variability. Ecology 2018, 99, 576-582. [CrossRef]

6. Sponseller, R.A.; Hall, S.J.; Huber, D.P.; Grimm, N.B.; Kaye, J.P.; Clark, C.M.; Collins, S.L. Variation in monsoon precipitation drives spatial and temporal patterns of Larrea tridentata growth in the Sonoran Desert. Funct. Ecol. 2012, 26, 750-758. [CrossRef]

7. Shukla, J. Interannual variability of monsoons. In Monsoons; Fein, J.S., Stephens, P.L., Eds.; John Wiley \& Sons: Hoboken, NY, USA, 1987; pp. 399-463. ISBN 978-0471874164.

8. Suepa, T.; Qi, J.; Lawawirojwong, S.; Messina, J.P. Understanding spatio-temporal variation of vegetation phenology and rainfall seasonality in the monsoon Southeast Asia. Environ. Res. 2016, 147, 621-629. [CrossRef] [PubMed]

9. Tao, F.; Yokozawa, M.; Zhang, Z.; Hayashi, Y.; Grassl, H.; Fu, C. Variability in climatology and agricultural production in China in association with the East Asian summer monsoon and El Niño Southern Oscillation. Clim. Res. 2004, 28, 23-30. [CrossRef]

10. Sultan, B.; Baron, C.; Dingkuhn, M.; Sarr, B.; Janicot, S. Agricultural impacts of large-scale variability of the West African monsoon. Agric. For. Meteorol. 2005, 128, 93-110. [CrossRef]

11. Gupta, A.; Anderson, D.; Pandey, D.; Singhvi, A. Adaptation and human migration, and evidence of agriculture coincident with changes in the Indian summer monsoon during the Holocene. Curr. Sci. 2006, 90, 1082-1090.

12. Justice, C.O.; Vermote, E.; Townshend, J.R.; Defries, R.; Roy, D.P.; Hall, D.K.; Salomonson, V.V.; Privette, J.L.; Riggs, G.; Strahler, A.; et al. The Moderate Resolution Imaging Spectroradiometer (MODIS): Land remote sensing for global change research. IEEE Trans. Geosci. Remote Sens. 1998, 36, 1228-1249. [CrossRef]

13. Wulder, M.A.; Loveland, T.R.; Roy, D.P.; Crawford, C.J.; Masek, J.G.; Woodcock, C.E.; Allen, R.G.; Anderson, M.C.; Belward, A.S.; Cohen, W.B.; et al. Current status of Landsat program, science, and applications. Remote Sens. Environ. 2019, 225, 127-147. [CrossRef]

14. Drusch, M.; Del Bello, U.; Carlier, S.; Colin, O.; Fernandez, V.; Gascon, F.; Hoersch, B.; Isola, C.; Laberinti, P.; Martimort, P.; et al. Sentinel-2: ESA's Optical High-Resolution Mission for GMES Operational Services. Remote Sens. Environ. 2012, 120, 25-36. [CrossRef]

15. Kokaly, R.F.; Clark, R.N.; Swayze, G.A.; Livo, K.E.; Hoefen, T.M.; Pearson, N.C.; Wise, R.A.; Benzel, W.M.; Lowers, H.A.; Driscoll, R.L.; et al. USGS Spectral Library Version 7; USGS: Reston, VA, USA, 2017.

16. Singer, R.B. Near-infrared spectral reflectance of mineral mixtures: Systematic combinations of pyroxenes, olivine, and iron oxides. J. Geophys. Res. Solid Earth 1981, 86, 7967-7982. [CrossRef]

17. Clark, R.N.; King, T.V.; Klejwa, M.; Swayze, G.A.; Vergo, N. High spectral resolution reflectance spectroscopy of minerals. J. Geophys. Res. 1990, 95, 12653. [CrossRef]

18. Rouse, J.; Haas, R.H.; Schell, J.A.; Deering, D.W. Monitoring vegetation systems in the Great Plains with ERTS. In Third Earth Resources Technology Satellite-1 Symposium-Volume I: Technical Presentations. NASA SP-351; Freden, S.C., Mercanti, E.P., Becker, M.A., Eds.; NASA: Washington, DC, USA, 1974; p. 309.

19. Lorenz, E. Statistical Forecasting Project, Scientific Report No. 1: Empirical orthogonal functions and statistical weather prediction; Masachusetts Institute of Technology: Cambridge, MA, USA, 1956.

20. Von Storch, H.; Zwiers, F.W. Statistical Analysis in Climate Research; Cambridge University Press: Cambridge, UK, 1999.

21. Bretherton, C.S.; Smith, C.; Wallace, J.M. An Intercomparison of Methods for Finding Coupled Patterns in Climate Data. J. Clim. 1992, 5, 541-560. [CrossRef]

22. Preisendorfer, R.W. Principal component analysis in meteorology and oceanography; Mobley, C.D., Ed.; Elsevier: Amsterdam, The Netherland, 1988.

23. Small, C. Spatiotemporal dimensionality and Time-Space characterization of multitemporal imagery. Remote Sens. Environ. 2012, 124, 793-809. [CrossRef]

24. Townshend, J.R.G.; Goff, T.E.; Tucker, C.J. Multitemporal dimensionality of images of normalized difference vegetation index at continental scales. IEEE Trans. Geosci. Remote Sens. 1985, GE-23, 888-895. [CrossRef] 
25. Shaw-Reade, S.N.; Sale, J.B.; Gallagher, M.D.; Daly, R.H. The Scientific Results of the Oman Flora and Fauna Survey 1977 (Dhofar). The Journal of Oman Studies Special Report No. 2; The Government Adviser for Conservation of the Environment: Muscat, Oman, 1977.

26. Thesiger, W. Across the empty quarter. Geogr. J. 1948, 111, 1-19. [CrossRef]

27. Thesiger, W. A further journey across the Empty Quarter. Geogr. J. 1949, 113, 21-44. [CrossRef]

28. Thomas, B. A journey into Rub' Al Khali: The southern Arabian desert. Geogr. J. 1931, 77, 1-31. [CrossRef]

29. Kwarteng, A.Y.; Dorvlo, A.S.; Vijaya Kumar, G.T. Analysis of a 27-year rainfall data (1977-2003) in the Sultanate of Oman. Int. J. Climatol. 2009, 29, 605-617. [CrossRef]

30. Hildebrandt, A. Ecohydrology of a seasonal cloud forest in Dhofar, Oman; Masachusetts Institute of Technology: Cambridge, MA, USA, 2005.

31. Hildebrandt, A.; Eltahir, E.A.B. Forest on the edge: Seasonal cloud forest in Oman creates its own ecological niche. Geophys. Res. Lett. 2006, 33, L11401. [CrossRef]

32. Hildebrandt, A.; Eltahir, E.A.B. Ecohydrology of a seasonal cloud forest in Dhofar: 2. Role of clouds, soil type, and rooting depth in tree-grass competition. Water Resour. Res. 2007, 43. [CrossRef]

33. Hildebrandt, A.; Al Aufi, M.; Amerjeed, M.; Shammas, M.; Eltahir, E.A.B. Ecohydrology of a seasonal cloud forest in Dhofar: 1. Field experiment. Water Resour. Res. 2007, 43. [CrossRef]

34. Hildebrandt, A.; Eltahir, E.A.B. Using a horizontal precipitation model to investigate the role of turbulent cloud deposition in survival of a seasonal cloud forest in Dhofar. J. Geophys. Res. Biogeosciences 2008, 113. [CrossRef]

35. Abdul-Wahab, S.A.; Al-Damkhi, A.M.; Al-Hinai, H.; Al-Najar, K.A.; Al-Kalbani, M.S. Total fog and rainwater collection in the Dhofar region of the Sultanate of Oman during the monsoon season. Water Int. 2010, 35, 100-109. [CrossRef]

36. Fallon, E. Mist Harvesting, Jebel Qara, Dhofar Province. Al Mawared Al Tabeieiah 1978, 4, 4-10.

37. Miller, A.G.; Morris, M. Plants of Dhofar: the southern region of Oman, traditional, economic and medicinal uses; Office of the Adviser for Conservation of the Environment, Diwan of Royal Court, Sultanate of Oman: Muscat, Oman, 1988; ISBN 715708082.

38. Patzelt, A. Synopsis of the flora and vegetation of Oman, with special emphasis on patterns of plant endemism. Jahrbuch 2014, 282-317.

39. Spalton, A.; Al Hikmani, H. The Arabian Leopards of Oman; Stacey International: London, UK; Diwan of Royal Court: Muscat, Oman, 2014; ISBN 9781-909022-34-8.

40. Small, C.; Sousa, D.; Kwarteng, A.; Spalton, A. Development of a Prototype for a Land Cover Monitoring System to Map Vegetation Change in the Dhofar Mountains of Oman. Available online: https://www.sqcc.org/ (accessed on 17 May 2019).

41. Pearson, K. LIII. On lines and planes of closest fit to systems of points in space. London, Edinburgh, Dublin Philos. Mag. J. Sci. 1901, 2, 559-572. [CrossRef]

42. Landgrebe, D.A. Machine Processing for Remotely Acquired Data. Available online: https://docs.lib.purdue. edu/cgi/viewcontent.cgi?article=1028\&context=larstech (accessed on 17 May 2019).

43. Piwowar, J.M.; Peddle, D.R.; LeDrew, E.F. Temporal mixture analysis of arctic sea ice imagery: A new approach for monitoring environmental change. Remote Sens. Environ. 1998, 63, 195-207. [CrossRef]

44. Galletti, C.S.; Turner, B.L.; Myint, S.W. Land changes and their drivers in the cloud forest and coastal zone of Dhofar, Oman, between 1988 and 2013. Reg. Environ. Chang. 2016, 16, 2141-2153. [CrossRef]

45. Sousa, D.; Small, C. Mapping and Monitoring Rice Agriculture with Multisensor Temporal Mixture Models. Remote Sens. 2019, 11, 181. [CrossRef]

46. Lobell, D.B.D.; Asner, G.G.P. Cropland distributions from temporal unmixing of MODIS data. Remote Sens. Environ. 2004, 93, 412-422. [CrossRef]

47. White, K.; Pontius, J.; Schaberg, P. Remote sensing of spring phenology in northeastern forests: A comparison of methods, field metrics and sources of uncertainty. Remote Sens. Environ. 2014, 148, 97-107. [CrossRef]

48. De Beurs, K.M.; Henebry, G.M. Spatio-Temporal Statistical Methods for Modelling Land Surface Phenology. In Phenological Research; Springer: Dordrecht, The Netherlands, 2010; pp. 177-208.

49. Zhang, X.; Friedl, M.A.; Schaaf, C.B. Global vegetation phenology from Moderate Resolution Imaging Spectroradiometer (MODIS): Evaluation of global patterns and comparison with in situ measurements. J. Geophys. Res. Biogeosci. 2006, 111. [CrossRef] 
50. Richardson, A.D.; Hufkens, K.; Milliman, T.; Aubrecht, D.M.; Chen, M.; Gray, J.M.; Johnston, M.R.; Keenan, T.F.; Klosterman, S.T.; Kosmala, M.; et al. Tracking vegetation phenology across diverse North American biomes using PhenoCam imagery. Sci. Data 2018, 5, 180028. [CrossRef]

51. Zhang, X.; Jayavelu, S.; Liu, L.; Friedl, M.A.; Henebry, G.M.; Liu, Y.; Schaaf, C.B.; Richardson, A.D.; Gray, J. Evaluation of land surface phenology from VIIRS data using time series of PhenoCam imagery. Agric. For. Meteorol. 2018, 256-257, 137-149. [CrossRef]

52. Tan, B.; Woodcock, C.; Hu, J.; Zhang, P.; Ozdogan, M.; Huang, D.; Yang, W.; Knyazikhin, Y. The impact of gridding artifacts on the local spatial properties of MODIS data: Implications for validation, compositing, and band-to-band registration across resolutions. Remote Sens. Environ. 2006, 105, 98-114. [CrossRef]

53. Fisher, J.B.; Whittaker, R.J.; Malhi, Y. ET come home: potential evapotranspiration in geographical ecology. Glob. Ecol. Biogeogr. 2011, 20,1-18. [CrossRef]

54. Fisher, J.B.; Melton, F.; Middleton, E.; Hain, C.; Anderson, M.; Allen, R.; McCabe, M.F.; Hook, S.; Baldocchi, D.; Townsend, P.A.; et al. The future of evapotranspiration: Global requirements for ecosystem functioning, carbon and climate feedbacks, agricultural management, and water resources. Water Resour. Res. 2017, 53, 2618-2626. [CrossRef]

55. Fisher, J.B.; Hook, S.J.; Allen, R.G.; Anderson, M.C.; French, A.N.; Hain, C.; Hulley, G.C.; Wood, E.F. ECOSTRESS: NASA'S Next-Generation Mission to Measure Evapotranspiration from the International Space Station; AGU: San Francisco, CA, USA, 2015.

56. Sousa, D.; Small, C. Spectral Mixture Analysis as a Unified Framework for the Remote Sensing of Evapotranspiration. Remote Sens. 2018, 10, 1961. [CrossRef]

(C) 2019 by the authors. Licensee MDPI, Basel, Switzerland. This article is an open access article distributed under the terms and conditions of the Creative Commons Attribution (CC BY) license (http://creativecommons.org/licenses/by/4.0/). 